\title{
A fragile site in the $X$ chromosome of the reindeer (Rangifer tarandus $\mathrm{L}$ )
}

\author{
U Gripenberg' ${ }^{1}$, S Huuhtanen ${ }^{1}$, M Wessman ${ }^{1}$, Nieminen $^{2}$ \\ 1 University of Helsinki, Department of Genetics, Arkadiankatu 7, SF-00100 Helsinki 10; \\ ${ }^{2}$ Finnish Game and Fisheries Research Institute, \\ Reindeer Research, SF-96100 Rovaniemi, Finland
}

(Proceedings of the 9th European Colloquium on Cytogenetics of Domestic Animals; Toulouse-Auzeville, 10-13 July 1990)

fraX / fragile site / reindeer / BrdU induction

\section{INTRODUCTION}

During an investigation on the heterochromatin in the reindeer (Rangifer tarandus) and some related species (Alces alces, Odocoileus virginianus and Dama dama) (Bianchi et al, 1990), bromodeoxyuridine (BrdU) was added to the lymphocyte cultures for the last 5 or $7 \mathrm{~h}$ of growth. In chromosome preparations from BrdUtreated cultures, a fragile site (fra) was observed in the $\mathrm{X}$ chromosome of the reindeer. The $\mathrm{X}$ chromosome of the reindeer is exceptionally large and very different from the X chromosome of other mammals. The fra site was located at the distal end of one of the arms of the nearly metacentric X chromosome. The fraX seemed to occur in a high proportion of the BrdU-treated cells. fra sites were not observed in any of the other species investigated. The accidental finding of fraX in the reindeer initiated a reexamination of slides from the reindeer cell cultures.

The chromosomes of 5 reindeer were investigated. Three subjects represented the semi-domesticated animal (Rangifer tarandus tarandus), two were wild forest reindeer (Rangifer tarandus fennicus). As has previously been shown (Gripenberg, 1984), no cytogenetic differences appear to exist between the two subspecies. BrdUtreated cultures and parallel cultures without BrdU were screened. Furthermore, a sixth reindeer (Rangifer tarandus fennicus) was investigated. In this case only chromosome preparations from cultures without BrdU were screened.

Lymphocytes were cultured according to standard methods. Pokeweed mitogen (PWM) was the preferred mitogen. BrdU $(20 \mu \mathrm{g} / \mathrm{ml})$ was added to the cultures for the last 5 or $7 \mathrm{~h}$ of growth. The chromosomes were G- and C-banded or stained with conventional Giemsa. Whenever possible, 100 metaphases were screened for the presence of fraX.

Figure 1 shows the G- and subsequently C-banded chromosomes of the reindeer (Gripenberg, 1984). The X chromosome is of 'the duplicate type' or comprises $9 \%$ of 
the total complement, while the mammalian X usually comprises $5 \%$ of the genome (Fraccaro et al, 1968).

Measurements of the length of the arms of X showed Xq to be $58 \%$ of the total length of X; large blocks of heterochromatin $-25 \%$ of the chromatin of the $\mathrm{X}$ chromosome - were located in Xq (fig 1). The length of Xp was $42 \%$ of X; the fra site was at the distal end of Xp (fig 2). It is worth noting that without the acquisition of the heterochromatin, the relation between the arm lengths would be the opposite: the fraX arm would be the long arm, Xq.

Due to extensive structural rearrangements in the $\mathrm{X}$ chromosome of the reindeer, bands or segments homologous with the human X can hardly be identified on the basis of cytological characteristics.

Table I shows the frequency of fraX in cells from 6 animals treated with BrdU for 0,5 or $7 \mathrm{~h}$. In cultures without any added BrdU, cells with fraX were only occasionally observed. Addition of BrdU for the last $5 \mathrm{~h}$ of growth apparently enabled incorporation into a smaller proportion of the cells; fraX was observed at a frequency less than $50 \%$. Cells incorporating BrdU for $7 \mathrm{~h}$ showed a fraX frequency in the range of $53-86 \%$ (mean $66 \%$ ). In females, the fra site is expressed in both $\mathrm{X}$ chromosomes in about half of the cells. fraX is often seen in both sister chromatids.

Table I. Frequency of fraX cells induced by BrdU in 6 reindeer cell cultures during 0,5 or $7 \mathrm{~h}$ of growth.

\begin{tabular}{ccccc}
\hline $\begin{array}{c}\text { Subject } \\
n o^{\mathrm{a}}\end{array}$ & Sex & $\begin{array}{c}\text { BrdU incorp } \\
(\mathrm{h})\end{array}$ & $\begin{array}{c}\text { No of cells } \\
\text { screened }\end{array}$ & \% fraX cells \\
\hline 1 & $\mathrm{M}$ & 7 & 100 & 53 \\
2 & $\mathrm{M}$ & 7 & 100 & 86 \\
3 & $\mathrm{~F}$ & 0 & 100 & 1 \\
& & 7 & 100 & 59 \\
4 & $\mathrm{~F}$ & 5 & 20 & 45 \\
5 & $\mathrm{~F}$ & 0 & 70 & 0 \\
& & 5 & 100 & 67 \\
6 & & 7 & 40 & 2 \\
\hline
\end{tabular}

${ }^{a}$ Subjects 1, 2 and 6 are wild forest reindeer, 3, 4 and 5 are semi-domesticated reindeer. M: male; F: female.

fra sites have so far been described in only a few animals (Sutherland and Ledbetter, 1988). In human cytogenetics, more than 100 fra sites are presently known and most of these sites are regarded as harmless chromosome variants. A notable exception is, however, the human fraX located at the distal end of the long arm (Xq27.3) and associated with transmissible mental retardation (Kähkönen, 1989).

The cytological similarity between the human fraX and the reindeer fraX is obvious. In reindeer, the original chromosome arm with the distal fra site could be either Xq or Xp as explained above. The human fraX is a rare folate-sensitive fragile 

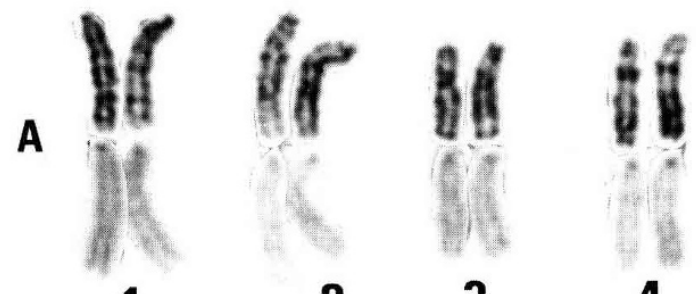

B $\begin{array}{ccc}1 & 2 & 3 \\ 48 & 98 & 80\end{array}$

8
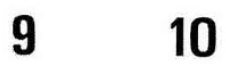

c

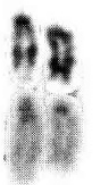

15

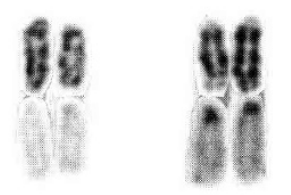

17

18
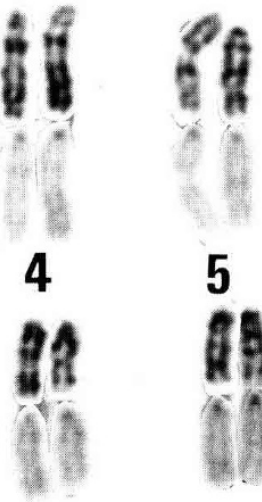

11

19
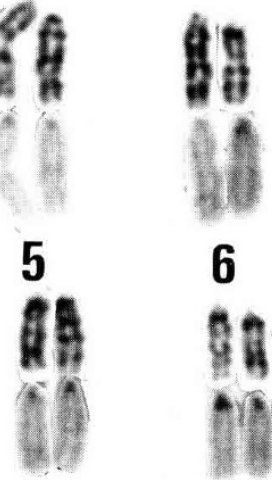

12
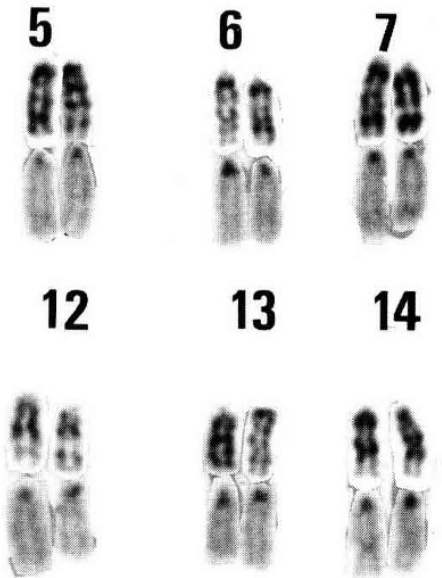

$13 \quad 14$
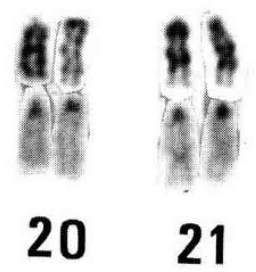
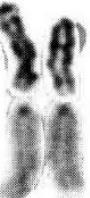

7

a

21
D

if

22

A6

E

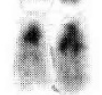

29

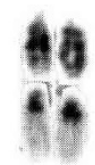

23

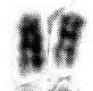

$7 \sqrt{6}$

30

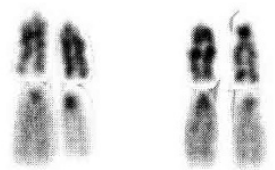

24

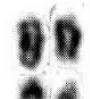

a.

31

32
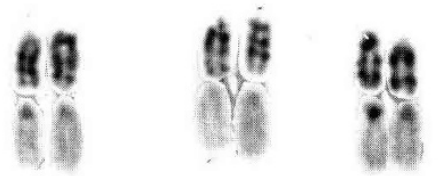

26

A 8

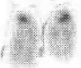

33

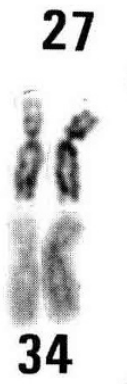


a

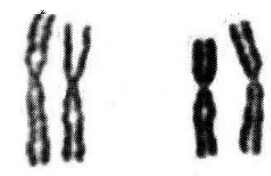

b
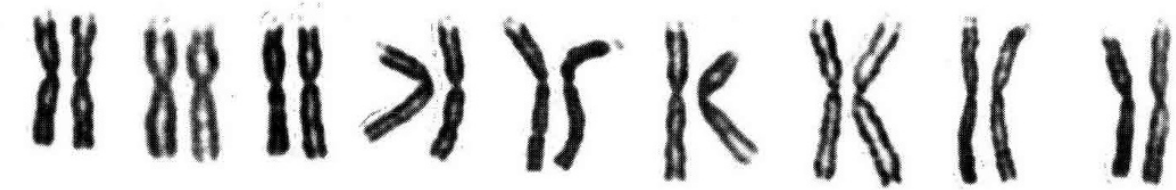

Fig 2. BrdU-induced fragile sites at the distal end of Xp. a. normal X chromosomes. b. fraX chromosomes.

site associated with mental retardation. The reindeer fraX, however, is a common BrdU-induced fra site. As far as it is known, the reindeer with fraX are normal in their appearance as well as in their behavior.

The biological significance of the fra sites is not known. It has, however, been pointed out that fra sites are cytogenetic manifestations of normal structural elements. Their significance for chromosome evolution has been discussed (Miró et $a l, 1987)$. fra sites can be regarded as recombinogenic hot spots causing inter- as well as intrachromosomal changes.

Whether the fra site of the reindeer $\mathrm{X}$ has contributed in some way to the structural changes in the chromosome arm in question is not known at present. However, the view that fraX in the reindeer is located at a site corresponding to the site of the human fraX seems possible. Homologies between human and reindeer $\mathrm{X}$ chromosomes remain to be further investigated.

\section{ACKNOWLEDGMENTS}

Drs MS and NO Bianchi have worked together with us on the same reindeer material and have also observed the fraX in the reindeer. Dr NO Bianchi has read the manuscript and has made valuable comments for which we are most grateful. This work has been supported by the Academy of Finland (SA 01/101), the Societas Scientiarum Fennica and the Finnish Cultural Foundation. We express our sincere thanks to Ms Tarja Välimäki and Ms Barbara von Schoultz, MSc, for skillful technical assistance. Helsinki Zoo has provided us with blood samples from the wild forest reindeer, for which we are most grateful to $\mathrm{Mr}$ H Jalanka DVM.

\section{REFERENCES}

Bianchi MS, Bianchi NO, Gripenberg U, Wessman M, Huuhtanen S (1990) Characterization of the heterochromatin in moose (Alces alces) chromosomes. Genetica 80, 1-7

Fraccaro M, Gustavsson I, Hultén M, Lindsten J, Tiepolo L (1968) Chronology of DNA replication in the sex chromosomes of the reindeer (Rangifer tarandus L). Cytogenetics 7, 196-211 
Gripenberg U (1984) Characterization of the karyotype of the reindeer (Rangifer tarandus); the distribution of the heterochromatin in the reindeer and the Scandinavian moose (Alces alces). In: Proc 6th Eur Colloq Cytogenet Domest Anim Zurich. (Stranzinger G, ed) 68-79 Kähkönen M (1989) Population cytogenetics of folate-sensitive fragile sites with special reference to mental retardation. Thesis, University of Oulu, Printing Center, Oulu Miró R, Clemente IC, Foster C, Egozcue J (1987) Fragile sites, chromosome evolution and human neoplasia. Hum Genet 75, 345-349

Sutherland GR, Ledbetter D (1988) Report of the Committee on Cytogenetic Markers. Human Gene Mapping 9.5, New Haven Conference, 1988. Cytogenet Cell Genet 49, 221-223 